\title{
Use of weight-bearing MRI for evaluating wheelchair cushions based on internal soft-tissue deformations under ischial tuberosities
}

\author{
Nogah Shabshin, MD; ${ }^{1}$ Gil Zoizner, BSc; ${ }^{2}$ Amir Herman, MD; ${ }^{3-4}$ Vlad Ougortsin, MD; ${ }^{3}$ Amit Gefen, PhD ${ }^{\text {* }}$ \\ ${ }^{1}$ Department of Diagnostic Imaging, Sheba Medical Center, Tel Hashomer, Israel; ${ }^{2}$ Sackler Faculty of Medicine, \\ Tel Aviv University, Tel Aviv, Israel; ${ }^{3}$ Department of Orthopaedic Surgery, Sheba Medical Center, Tel Aviv, Israel; \\ ${ }^{4}$ Department of Statistics, University of Haifa, Mount Carmel, Haifa, Israel; ${ }^{5}$ Department of Biomedical Engineering, \\ Faculty of Engineering, Tel Aviv University, Tel Aviv, Israel
}

\begin{abstract}
Deep tissue injury (DTI) is a severe type of pressure ulcer, in which damage initiates under intact skin, in soft tissues that are mechanically deformed by load-bearing bony prominences. Sitting-acquired DTI typically occurs in the gluteus muscles that could sustain deformations by the weightbearing ischial tuberosities (ITs). No clinical method currently exists for measuring internal tissue deformations; so design and selection of wheelchair cushions are based mostly on measuring sitting pressures. Our objective was to evaluate the influence of different commercial cushions on internal soft-tissue deformations under the ITs, using weight-bearing magnetic resonance imaging (MRI). We specifically compared muscle, superficial fat, and effective (muscle and fat together) tissue deformations while subjects ( $n=10)$ sat on four cushions (two viscoelastic and two foam) and directly on a rigid support. Deformations were maximal in muscle tissue (mean $\sim 70 \%$ ), twice more the amount than in fat ( 30\%). Effective soft-tissue deformations were $\sim 50 \%$ to $\sim 60 \%$. Although cushions mildly reduced muscle deformations in the order of $10 \%$, theoretically, our interpretation suggests that this deformation level adds safe sitting time. This study demonstrated that weightbearing MRI is applicable for evaluating wheelchair cushions and, in the future, may be a tool to systematically support cushion design and selection.
\end{abstract}

Key words: bedsores, decubitus, deep tissue injury, foam, open MRI, pressure sores, pressure ulcer, rehabilitation, sitting pressures, viscoelastic.

\section{INTRODUCTION}

Pressure ulcers are a major cause of morbidity and mortality, particularly in individuals who use a wheelchair because of neuromuscular disorders. The lifetime risk for developing a pressure ulcer in this population was estimated to be 25 to 85 percent [1]. Furthermore, the cost of treatment of pressure ulcers exceeds $\$ 1$ billion annually in the United States alone [2]. Thus, prevention of this pathology is crucial.

Recently, research has shown that many of the pressure ulcers previously classified as stage 3 or stage 4 (severe) are actually a distinct category, now defined by the National Pressure Ulcer Advisory Panel (Washington, DC) (www.npuap.org) as a deep tissue injury (DTI) [34]. The pathophysiological mechanism of DTI is completely distinct from that of superficial pressure ulcers. The injury initiates in deep soft tissues, probably in skeletal

Abbreviations: ANOVA $=$ analysis of variance, DTI $=$ deep tissue injury, IT = ischial tuberosity, $\mathrm{MR}=$ magnetic resonance, MRI = MR imaging, RCT = randomized controlled trial.

*Address all correspondence to Amit Gefen, PhD; Department of Biomedical Engineering, Faculty of Engineering, Tel Aviv University, Tel Aviv 69978, Israel; +972-3-6408093; fax: +972-3-640-5845. Email: gefen@eng.tau.ac.il DOI:10.1682/JRRD.2009.07.0105 
muscle tissue that is mechanically deformed directly by weight-bearing bony prominences [5]. Most of the sitting-acquired DTI cases occur in the gluteus muscles that are subject to sustained deformations by the weight-bearing ischial tuberosities (ITs) during sitting [5]. Necrosis of the deep and superficial soft tissues around the IT may be present in such DTI cases under intact skin and before skin changes occur [3,6-7].

Numerous types of wheelchair cushions are available commercially, and nearly all claim to prevent, or at least delay, pressure ulcer development of all kinds, including DTI. Selecting a cushion for an individual is a complex process that involves comfort, postural, functional, and safety considerations, which do not always coincide [8]. The number of randomized controlled trials (RCTs) that tested the efficacy of prevention with a clinical outcome is low, and so such studies do not show a consensus regarding superior performances of a certain cushion [9]. These RCT studies are also difficult to conduct, mostly because-

1. High sample sizes are required (e.g., because of difficulties in recruiting suitable subjects, high drop-out rates, and sometimes low incidence rates of pressure ulcers or DTI during the study period).

2. Pressure ulcers and DTIs should be definitively and timely identified, but this is not straightforward, e.g., because of the nature of DTIs that is concealed at early stages.

3. Problems exist in isolating the effect of the cushion from other interfering clinical variables (e.g., comorbidities that are common in populations susceptible to pressure ulcers), environmental factors, and performance of the caregivers [9-11].

Various objective parameters, including contact pressures during sitting, buttocks skin temperatures, and humidity, have been used to evaluate the efficacy of cushions in preventing pressure ulcers [12], with contact pressure measurements being the most popular tool. However, no agreed threshold for the allowed sitting pressure exists in the literature, as explained in recent articles stating that internal anatomy and mechanical properties of tissues can cause substantial differences in internal tissue loading between individuals, even when their sitting pressures are similar [13-15].

Increasing evidence shows that DTI develops in deep tissues because of sustained mechanical deformations that damage cells directly as well as obstruct blood flow [16-18]; however, no quantitative noninvasive clinical method exists for measuring internal mechanical condi- tions in deep tissues. In a previous basic science study, we used magnetic resonance imaging (MRI) to demonstrate internal soft-tissue deformations in the buttocks during weight-bearing sitting [14-15]. In the current study, we sought to use a similar method to evaluate the influence of different types of commercial wheelchair cushions on internal tissue deformations in the buttocks, under the IT. Specifically, we compared muscle, superficial fat, and overall soft-tissue deformations under the IT while subjects sat on different types of commercial cushions (viscoelastic, foam) and directly on a rigid support, within an open-magnetic resonance (MR) system.

\section{METHODS}

\section{Subjects}

Ten nondisabled volunteers were recruited: seven males and three females. Subjects were aged $33 \pm 5$ years (values are shown as mean \pm standard deviation throughout the article unless otherwise stated). Their height and weight were $177 \pm 5 \mathrm{~cm}$ and $73.5 \pm 10.9 \mathrm{~kg}$, respectively, giving a body mass index of $23.5 \pm 3.2 \mathrm{~kg} / \mathrm{m}^{2}$. All subjects had average body habitus. Exclusion criteria included absolute and relative contraindication for MRI, e.g., cardiac pacemakers (or other metallic implants) or metallic foreign bodies, as well as pregnancy, claustrophobia, psychiatric disorders, and limitations on sitting still for prolonged time periods. We further excluded subjects with known underlying diseases that impair mobility and those with a history of pelvic fractures or pelvic surgery.

\section{MRI Scan Protocol}

Subjects were scanned on a $0.5 \mathrm{~T}$ open MR system (Signa SP, GE Medical Systems; Milwaukee, Wisconsin). This system has a "double-donut" configuration that allows subjects to sit in the magnet, between the two donuts. Images of the buttocks were obtained with coronal T1-weighted images ${ }^{*}$ (time of repetition/time of echo = $440 / 28$, field of view $=240 \mathrm{~mm}$, slice thickness $=4 \mathrm{~mm}$ ). We used T1-weighted images because they provide the best anatomic contrast: fat shows high-intensity signal, whereas skeletal muscle and fluid show low signal. All

\footnotetext{
*"T1" is a time constant that indicates mode of MRI scans. T1weighted imaging is one of the basic types of MRI contrast commonly used in clinical scans for demonstrating soft-tissue structures.
} 
scan images, which are common sites for sitting-acquired pressure ulcers and DTI, were focused on the IT [5].

Subjects were first scanned in a neutral non-weightbearing sitting posture and then again while sitting on four different cushions as described in the next section. For the non-weight-bearing scan, subjects were asked to sit neutrally (upright, relaxed) on an air-inflated rubber tire placed on the MRI table so that the buttocks region under the IT was unloaded. A flexible MRI coil was placed under the tire. Next, the tire was removed and subjects were scanned again in a weight-bearing posture, while sitting on a custom-made, MR-compatible chair designed for this purpose (Figure 1), simulating a wheelchair (wheelchairs contain metallic components and therefore could not be used for the MRI studies). The chair was made of plastic, with an erect backrest and a buttocks support area that was $61 \mathrm{~cm}$ wide (which fitted exactly in the MRI space between the magnet parts). We further used armrests and footrests to simulate a wheelchair sitting posture (Figure 1(a)), but the (nondisabled) subjects were instructed to use the armrests/footrests for comfortable sitting, rather than for supporting their body weight. The chair was mounted on the MR table and was used in the weight-bearing sitting MR scans (Figure 1(b)). Each subject underwent five weight-bearing scans: sitting directly on the chair (rigid support) and then on each of four cushions (details in the following section). While cushions were replaced, subjects were asked to lift their buttocks as minimally as possible to avoid major postural changes. Markers on the chair were used to maintain comparable buttocks positions for each cushion placed on the chair by aligning the midline of the body with a frontal marker on the chair and the greater trochanter with a lateral marker on the chair.

\section{Cushions}

Four cushions were selected for the study: two standard commercial viscoelastic cushions (A and B) and two standard commercial foam cushions (C and D), with thicknesses and mechanical properties as specified in Table 1. The elastic modulus of each cushion was measured before the MRI trials in a laboratory setting. Specifically, we tested viscoelastic cushion A in an indentation test configuration using a half-spherical indenter attached to an electromechanical uniaxial testing machine (Instron 5544; High Wycombe, United Kingdom), which deformed the cushion at a rate of $20 \mathrm{~mm} / \mathrm{min}$. We calculated the long-term elastic moduli of cushion A using the Hertz solution for this indenter-cushion contact problem, as described by Agam and Gefen for indentation strains of 60, 70, and 80 percent [19] (typical cushion strains under a body weight [20]), after allowing 1 minute of stress

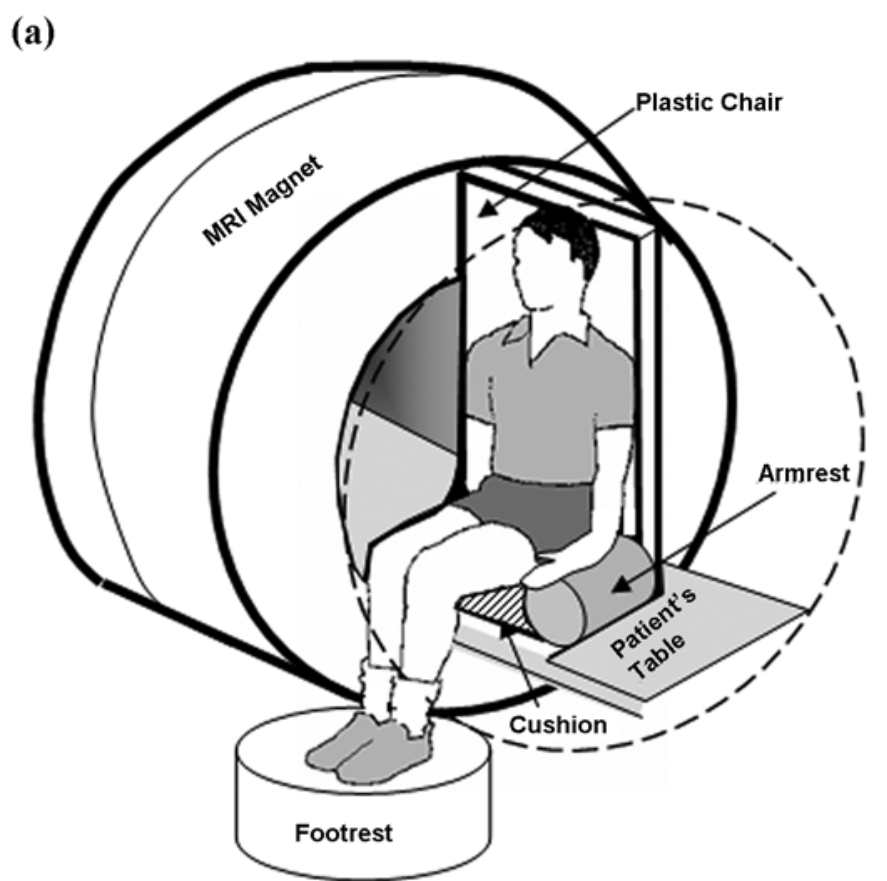

(b)

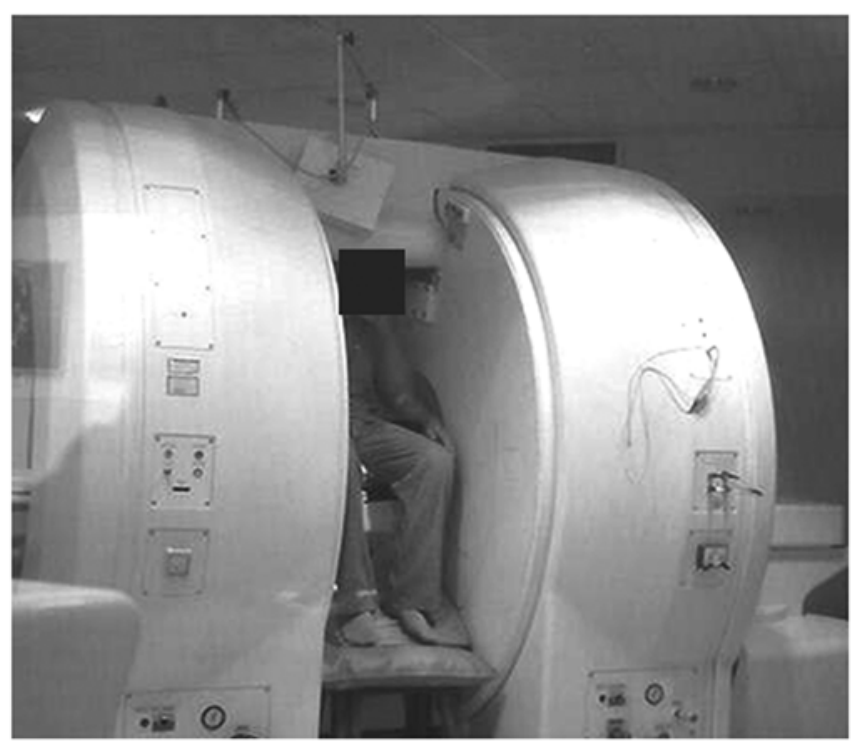

Figure 1.

Experimental design of magnetic resonance imaging (MRI) studies: (a) scheme and (b) photograph of subject sitting in MRI. 
JRRD, Volume 47, Number 1, 2010

Table 1.

Properties of cushions used in study.

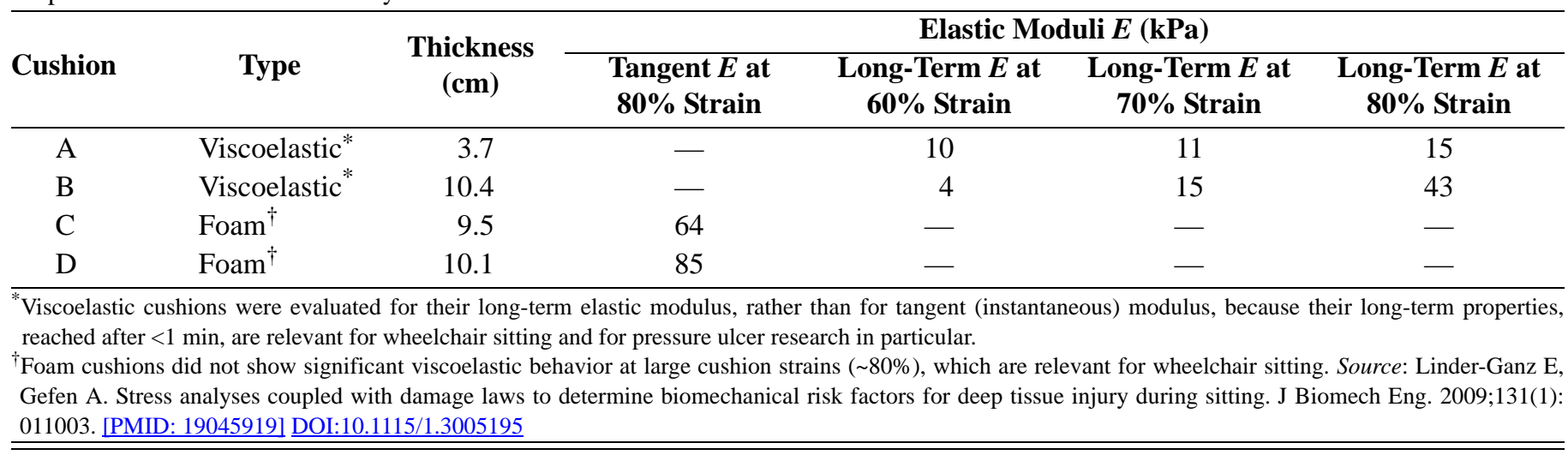

relaxation. Cushions B, C, and D were tested in a compression configuration. Material specimens of $6.5 \times 6.5 \times$ $6.5 \mathrm{~cm}$ were cut from each cushion. The specimen from cushion B, which is also marketed as a viscoelastic cushion (Table 1), was tested for long-term elastic moduli at 60,70 , and 80 percent strain, similarly to the test protocol for cushion A. The specimens from the foam cushions $\mathrm{C}$ and $\mathrm{D}$ were compressed up to 80 percent strain, again at a rate of $20 \mathrm{~mm} / \mathrm{min}$, and their tangent (instantaneous) elastic moduli recorded. Tangent moduli were recorded for cushions $\mathrm{C}$ and $\mathrm{D}$ since, unlike the viscoelastic cushions $\mathrm{A}$ and $\mathrm{B}$, cushions $\mathrm{C}$ and $\mathrm{D}$ did not show substantial viscoelastic behavior (i.e., stress relaxation) at large cushion strains (Table 1).

\section{Sitting Pressures}

In separate studies, we recorded contact pressures at the IT regions of subjects while they were sitting on each of the cushions A, B, C, and D (Table 1), which were placed on the same plastic chair used in the MRI setting. We measured contact pressures at a rate of $1 \mathrm{~Hz}$, using a commercial pressure mat that was placed in between the buttocks and the cushion/support. We used a Tactilus ${ }^{\circledR}$ pressure mat (Sensor Products Inc; Madison, New Jersey) that contained 256 piezoelectric sensors, each $2.5 \times$ $2.5 \mathrm{~cm}^{2}$, with a capacity of $141 \mathrm{~kg} / \mathrm{cm}^{2}$, accuracy of \pm 10 percent, repeatability of \pm 2 percent, hysteresis of \pm 5 percent, and nonlinearity of \pm 1.5 percent. The creep and hysteresis effects inherent to the sensors were automatically corrected by the Tactilus ${ }^{\circledR}$ software. Contact pressures were not acquired during the actual MRI scans because of electromagnetic interferences between the pressure mat and MRI. We acquired peak contact pressures under the IT and average pressures across the buttocks-cushion contact area.

During the sitting pressure studies, subjects were also asked to select the most comfortable cushion and the least comfortable cushion.

\section{MR Data Analysis}

Tissue deformations were calculated from the MR scans, separately for the gluteus muscles, the superficial fat tissue (between muscle and skin), and the muscle and fat together as one effective "soft-tissue" material (Figure 2). Tissue deformations were calculated as follows: for muscle, we first obtained the nondeformed thickness from the non-weight-bearing MRI scan by measuring the distance from the apex of the IT vertically to the muscle-fat boundary, $M_{n}$. We obtained the deformed muscle thickness in the same subject from a weight-bearing MRI (for a given support/cushion) by again measuring the distance from the IT to the muscle-fat boundary, $M_{w}$. The percentage of muscle deformation was calculated as $\% M=\left(M_{n}-\right.$ $\left.M_{w}\right) / M_{n}$. Similarly, for superficial fat tissue, we measured the distance from the muscle-fat boundary directly under the projection of the IT to the skin, in the non-weightbearing $\left(F_{n}\right)$ and weight bearing $\left(F_{w}\right)$ MRI scans and calculated the percentage of fat deformation as $\% F=$ $\left(F_{n}-F_{w}\right) / F_{n}$. For effective soft-tissue deformation, we measured the distance between the apex of the IT and skin in the non-weight-bearing $\left(S_{n}=M_{n}+F_{n}\right)$ and weight-bearing $\left(S_{w}=M_{w}+F_{w}\right)$ MRI scans and calculated the percentage of effective soft-tissue deformation as $\% S=\left(S_{n}-S_{w}\right) / S_{n}$. The anatomical landmarks for calculating these tissue thicknesses and deformations are summarized in Table 2 and shown also in Figure 2. We calculated $\% M, \% F$, and $\% S$ separately for the left and 

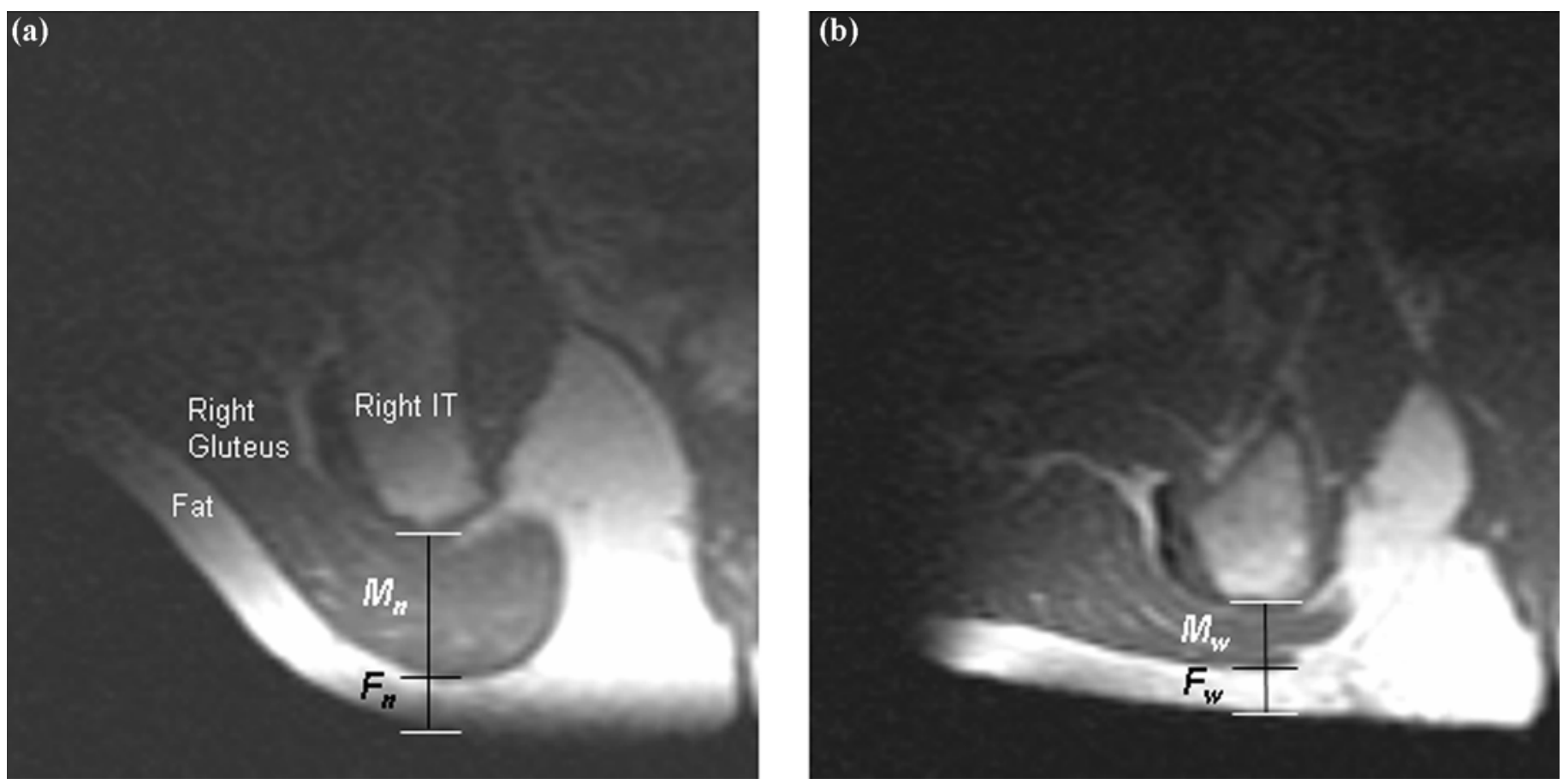

Figure 2.

Magnetic resonance imaging scan example of right buttocks in (a) non-weight-bearing and (b) weight-bearing positions, with muscle ( $M_{n}$ and $\left.M_{w}\right)$ and fat $\left(F_{n}\right.$ and $\left.F_{w}\right)$ tissue thicknesses marked on images. IT = ischial tuberosity.

right body sides and then averaged each outcome measure between the body sides of each subject to increase the statistical power of the statistical tests described next.

\section{Statistical Analysis}

We obtained descriptive statistics (mean and standard deviations) for peak contact pressures under the IT, average sitting pressures, $\% M, \% F$, and $\% S$ in the subject group. We conducted a one-way analysis of variance (ANOVA) for the factor of support type (cushions A, B, C, or $\mathrm{D}$ or rigid support) to determine whether peak contact pressures differed across supports. We then conducted a

Table 2.

Anatomical landmarks for calculating tissue thicknesses in nonweight-bearing and weight-bearing sitting postures (see also Figure 2).

\begin{tabular}{lll}
\hline \multirow{2}{*}{ Tissue Type } & \multicolumn{2}{c}{ Anatomical Landmark } \\
\cline { 2 - 3 } & \multicolumn{1}{c}{ First } & \multicolumn{1}{c}{ Second } \\
\hline Muscle & $\begin{array}{l}\text { Apex of ischial } \\
\text { tuberosity (IT) }\end{array}$ & $\begin{array}{l}\text { Muscle-fat boundary } \\
\text { under projection of IT }\end{array}$ \\
Fat & $\begin{array}{l}\text { Muscle-fat boundary } \\
\text { under projection of IT }\end{array}$ & Skin \\
Effective Soft & Apex of IT & Skin \\
\hline \hline
\end{tabular}

similar ANOVA for the average pressures. Likewise, we conducted separate ANOVA tests for $\% M, \% F$, and $\% S$ to determine whether each parameter differed across supports. For each ANOVA, a corresponding post hoc TukeyKramer multipairwise comparison followed for determining specific differences between variables across supports. A value of $p<0.05$ was considered statistically significant.

\section{RESULTS}

Peak and average contact pressure data (Figure 3) for each of the cushions are reported in Table 3 . The rigid support induced the highest peak contact pressure, which was approximately 2.4 times greater than the mean of peak contact pressures induced by all cushions $(p<0.01$, Table 3). The viscoelastic cushion A, which was the thinnest cushion studied herein (Table 1), induced average contact pressures (across the buttocks-cushion contact area) that were about 1.3 times higher than pressures of other cushions ( $p<0.05$, Table 3). The Tukey-Kramer comparisons specifically indicated that when any type of cushion was used, peak pressures were consistently lower than rigid support pressures $(p<0.01)$ and that thin cushion A 
(a)

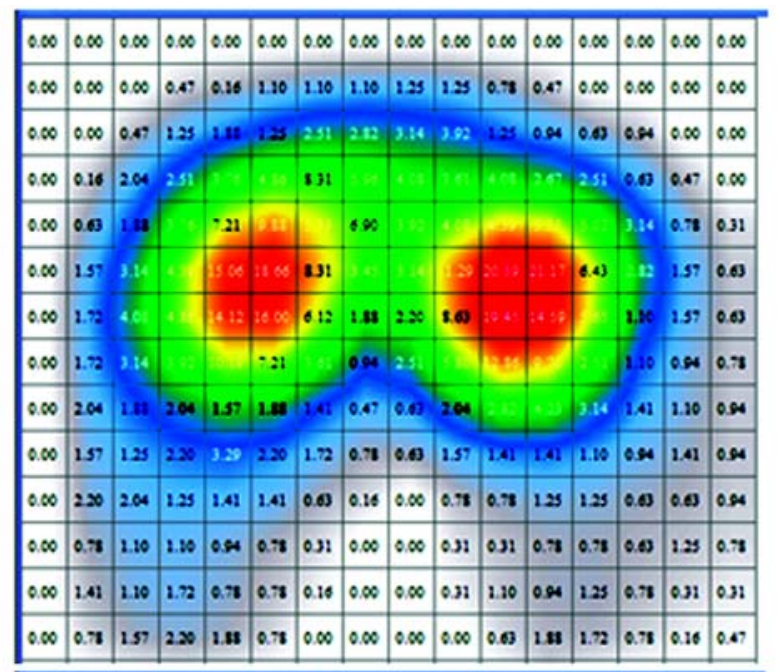

(c)

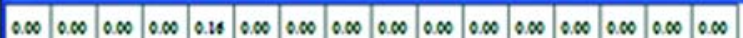
\begin{tabular}{lllllllllllllllll}
0.00 & 0.00 & 0.00 & 0.16 & 0.31 & 0.3 & 1.30 & 0.04 & 0.07 & 0.31 & 0.31 & 0.31 & 0.16 & 0.00 & 0.00 & 0.00 \\
\hline
\end{tabular}

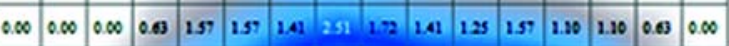

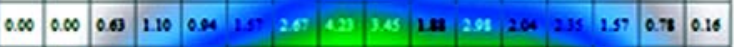

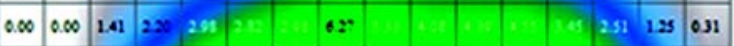

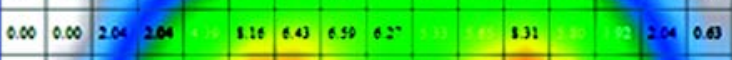

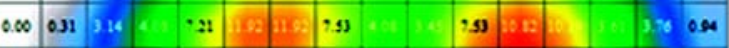

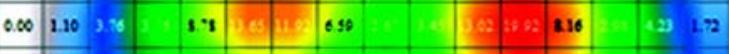

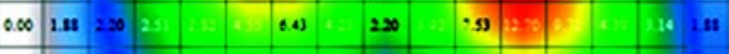

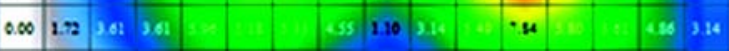

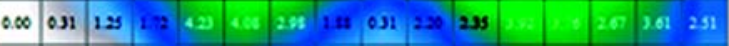

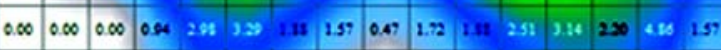

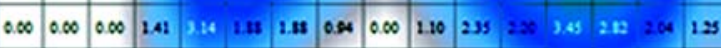

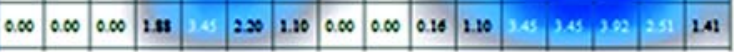

(e)

\begin{tabular}{|c|c|c|c|c|c|c|c|c|c|c|c|c|c|c|c|}
\hline 0.00 & 0.00 & $0 . \infty$ & 0.00 & 0.00 & 0.00 & 0.00 & 0.00 & 000 & 0.00 & 0.00 & 0.00 & 0.00 & 0.00 & $0, \infty$ & 0.00 \\
\hline$\infty$ & 0.00 & 0.00 & 000 & 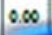 & 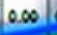 & 0.10 & 0.03 & 120 & $0 . \infty$ & 0.00 & 0.00 & 0.00 & 0.00 & 0.00 & 0.00 \\
\hline$\infty$ & 0.00 & 0.00 & $0 . \infty$ & & & & 10 & 278 & & DSA & & c & 0.00 & $0 \infty \infty$ & 0.00 \\
\hline 0.0 & 0.00 & 0.00 & 210 & 18 & & & 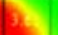 & & 0.03 & & , & & 1. & 0.16 & 0.00 \\
\hline$\infty$ & 0.00 & 0.83 & 157 & $2, \infty$ & $\therefore x$ & 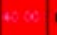 & $\infty \infty$ & & ond & fit: & 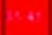 & & & $\theta$ & 000 \\
\hline $0 . \infty$ & 0.00 & 0.47 & oen & 235 & & & an: & $15^{\circ}$ & 8 & 4 & & & & 172 & 0.31 \\
\hline$\infty$ & 0.00 & 0.47 & 1.16 & 20 & 14 & & 1.48 & & 1.41 & & & & 0.9 & ors & 0.16 \\
\hline$\infty$ & 0.78 & 2.20 & $0 ., 7$ & 2.20 & res & 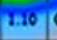 & 0.31 & 0.00 & 0.80 & 1.72 & Liz & oee & 0.03 & 0.03 & $0 ., 8$ \\
\hline 0.00 & 0.00 & 0.16 & 0.16 & 0.16 & 0.00 & 0.16 & 0.00 & $0 . \infty$ & 0.00 & 0.78 & 0.03 & 0.47 & $0 . \infty$ & 0.16 & 0.00 \\
\hline 0.00 & 0.16 & 0,4 & OSA & 0.0 & 0, & $0 . \infty$ & 0.00 & $0 . \infty$ & 0.00 & $0 ., 1$ & 0.4 & 0.16 & 0.16 & $0 . \infty$ & 0.00 \\
\hline 0.00 & 0.16 & 0,31 & 0.16 & 0.16 & 0.42 & 0.00 & $0 . \infty$ & 0.00 & $0 . \infty$ & 0.00 & 0.00 & 0.00 & 0.26 & 0.16 & 0.00 \\
\hline 0.0 & 0.31 & 0.31 & 0.47 & 0.31 & 0.31 & 0.00 & 0.00 & 0.00 & 0.00 & 0.16 & 0.4 & 0.16 & 0.16 & 0.16 & 0.00 \\
\hline $0 . \infty$ & 0.0 & 0.78 & 0.03 & 0.4 & 0.16 & 0.00 & $0 . \infty$ & $0 . \infty$ & 0.00 & 0.00 & os: & 0.47 & 0.16 & 0.16 & $00 \infty$ \\
\hline 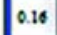 & O.s. & 1.72 & 1.10 & 1.20 & 0.16 & 0.00 & 0.00 & $0 . \infty$ & $0 . \infty$ & 0.16 & 125 & 1.10 & 0.87 & 0.16 & 0.00 \\
\hline
\end{tabular}

(b)

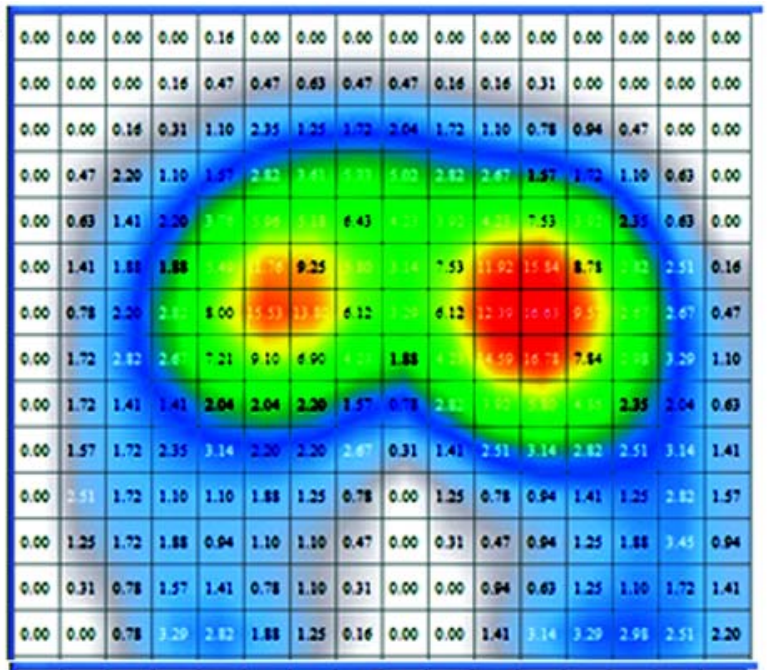

(d)

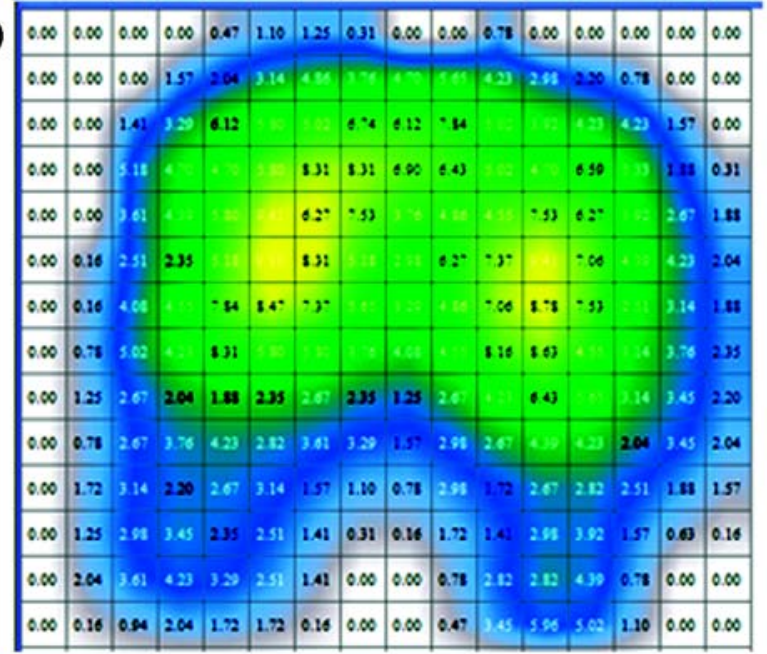

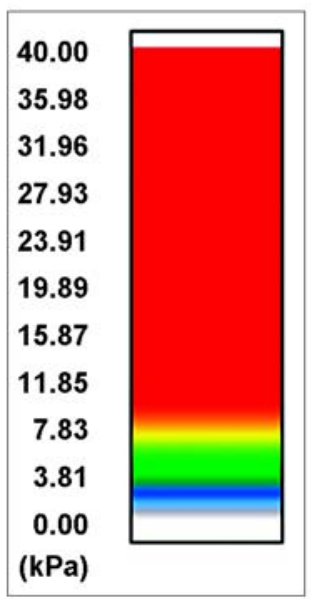

Figure 3.

Example of sitting pressure distributions of same subject (male, aged $34 \mathrm{yr}$, weight $87 \mathrm{~kg}$, body mass index $26 \mathrm{~kg} / \mathrm{m}^{2}$ ) seated on four studied cushions, (a) viscoelastic A, (b) viscoelastic B, (c) foam C, and (d) foam D, and on (e) rigid support. 
Table 3.

Contact pressures (mean \pm standard deviation) under ischial tuberosities for subjects $(N=10)$ while sitting on each studied cushions.

\begin{tabular}{lcc}
\hline \multicolumn{1}{c}{ Cushion } & $\begin{array}{c}\text { Peak Pressure } \\
\mathbf{( k P a )}\end{array}$ & $\begin{array}{c}\text { Average Pressure } \\
\text { Over Buttocks- } \\
\text { Cushion Contact } \\
\text { Area (kPa) }\end{array}$ \\
\hline Viscoelastic A & $21.6 \pm 9.6$ & $3.9 \pm 1.8^{*}$ \\
Viscoelastic B & $15.2 \pm 6.9$ & $2.6 \pm 0.4$ \\
Foam C & $13.3 \pm 5.7$ & $2.4 \pm 0.5$ \\
Foam D & $11.1 \pm 3.1$ & $2.5 \pm 0.5$ \\
Rigid Support & $36.5 \pm 7.5^{\dagger}$ & $3.3 \pm 0.6$ \\
${ }^{*} p<0.05$ in single-factor analysis of variance (ANOVA). \\
${ }^{\dagger} p<0.01$ in single-factor ANOVA. \\
\hline \hline
\end{tabular}

induced significantly higher peak pressures than those of thicker cushion D (Table 3). Subjects ranked viscoelastic cushion A equally as being the most comfortable and the least comfortable cushion.

Tissue deformations for muscle $(\% M)$, fat $(\% F)$, and effective soft tissue $(\% S)$ are plotted in Figure 4 for the four cushions characterized in Table 1, as well as for the rigid support. We found that the percentage of muscle tissue deformation was more than twofold that of fat tissue, regardless of the support type (Figure 4(a) and (b)). Mean values of muscle tissue deformations ranged between 64 and 72 percent across supports, whereas fat tissue deformations ranged between 23 and 35 percent (Figure 4(a) and (b)). The mean of effective soft-tissue deformations (muscle plus fat) ranged between 50 and 59 percent (Figure 4(c)).

The mean values of all deformation outcome measures were lower while cushions were used, with respect to the rigid support, but only foam cushion D induced statistically significant lower data $(p<0.03)$ for effective soft-tissue deformations. Generally, the mean of $\% M$, $\% F$, and $\% S$ for the viscoelastic cushions was slightly higher than for the foam cushions, but these differences were not statistically significant. Tukey pairwise comparisons identified a statistically significant difference only for the $\% S$ measure and, for this measure, only between the foam cushion $\mathrm{D}$ (the relatively stiffest, with tangent elastic modulus of $85 \mathrm{kPa}$ at $80 \%$ strain; Table 1) and the rigid support (Figure 4(c)). Overall, the data in Figure 4 show that commercial viscoelastic or foam cushions reduce deep-tissue deformations in nondisabled individuals in the order of 10 percent, at best, with respect to tissue
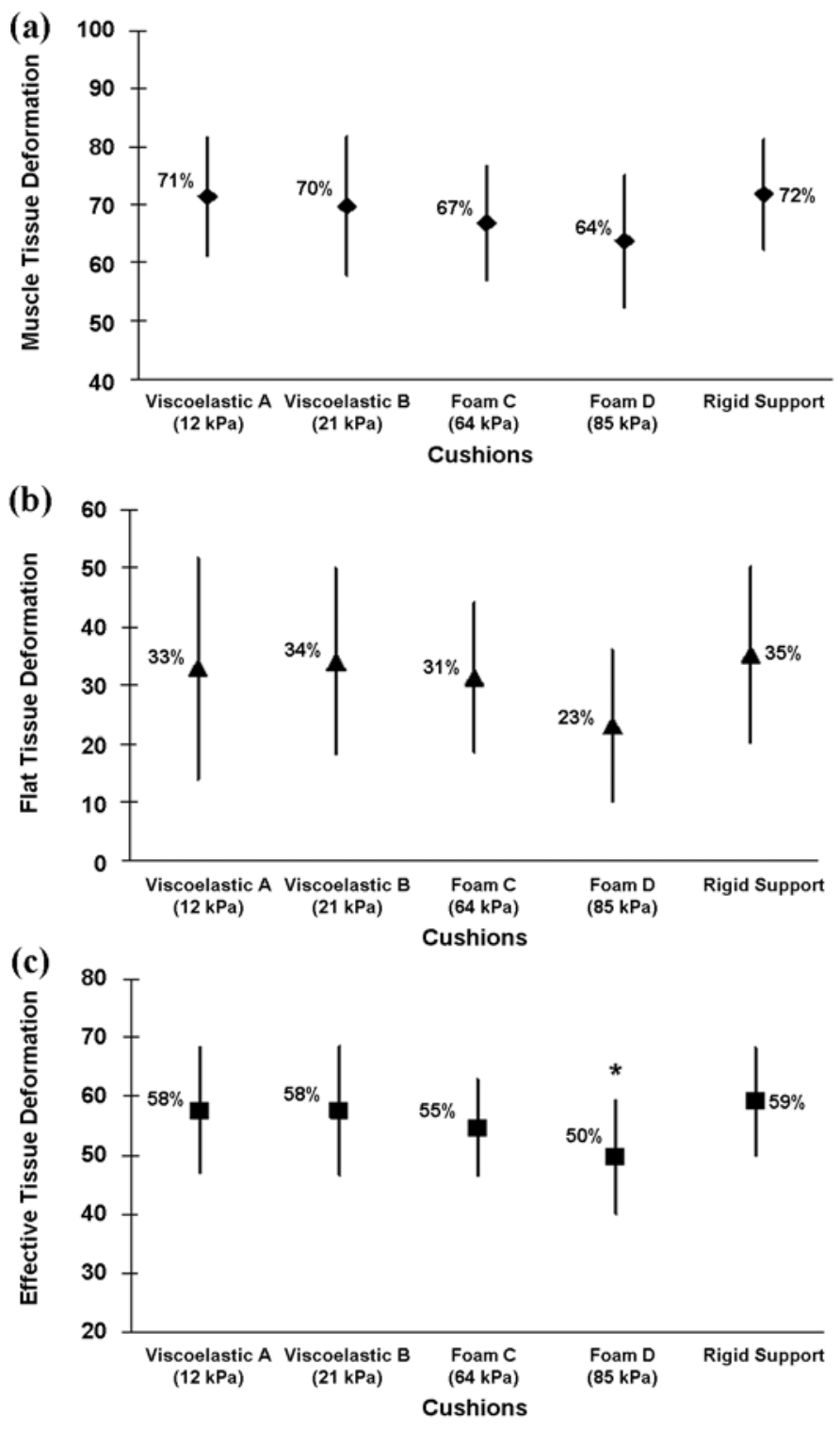

Figure 4.

Tissue deformations (\%) of (a) muscle, (b) fat, and (c) effective soft tissue (muscle and fat together) for all support surfaces. ${ }^{*} p<0.03$.

deformations induced by the rigid support. Specifically, for the best-performing cushion, foam $\mathrm{D}$, deformations reduced by 8,12 , and 9 percent for $\% M, \% F$, and $\% S$, respectively, compared with those of the rigid support (Figure 4). Analysis of individual subject data, where extents of individual differences between $\% M, \% F$, and $\% S$ for each given cushion and corresponding parameters for the rigid support were studied, confirmed that internal tissue deformations while cushions were used were reduced by up to approximately 10 percent for each individual. 


\section{DISCUSSION}

We found that commercial cushions reduced internal tissue deformations, surprisingly, in the order of only 10 percent (Figure 4). Specifically, effective soft-tissue deformations (muscle plus fat) were around 50 to 60 percent, in the same order of range when subjects were sitting on either cushions or the rigid support (Figure 4). The most rigid cushion evaluated in this study (foam D, Table 1) induced the greatest (statistically significant) decrease in soft-tissue deformations (Figure 4(c)), consistent with the measured contact pressures, which provided relatively low peak pressure recordings for this particular cushion (Figure 3, Table 3). The MRI-based method clearly demonstrated soft-tissue deformations in all subjects and consistently provided quantitative measures of $\% M, \% F$, and $\% S$.

In this study, we determined localized soft-tissue deformations directly under the IT. Soft tissues such as muscle and fat are nearly incompressible because of high liquid content; so sagging of the IT into the soft tissues during weight-bearing causes lateral expansion of the muscles and fat. This result has been observed in previous MRI studies [14-15]. In addition, previous articles indicated that soft-tissue deformations maximize under the IT [14-15,21]. From a clinical point of view, DTI typically develops under the IT [5]; therefore, we focused on this anatomical area of interest.

Although a reduction of internal tissue deformations in the order of 10 percent when one sits on a cushion may seem to be negligibly significant clinically, this interpretation might not be true. Gefen et al. determined "safe" and cell-death-inducing deformations for skeletal muscles by applying compressive deformations to tissueengineered muscle constructs and by fluorescently staining the permanently damaged cells in these constructs over time [22]. They found that exposure to deformations exceeding 77 percent caused immediate muscle cell death in the constructs (Figure 5). This critical deformation level decreased mildly over the first hour of continuous compression and after, which decreased rapidly, so that following 3 hours of continuous compression, even cells subjected to deformations of 52 percent died (Figure 5). To demonstrate a theoretical implication of the present findings on muscle cell viability in prolonged sitting with or without a cushion, we used the cell-death tolerance of Gefen et al. [22]. The rationale for analysis is that hierarchical computer modeling previously showed that high deformations at the tissue continuum scale are associated with high cell deformations [23]. Based on this result, we expect that the localized elevated muscle and fat deformations presently observed in this MRI study also substantially distort cells in soft tissues under the IT.

As an example, we integrated a theoretical implication of the data from this study with the muscle cell death threshold of Gefen et al. [22]. Referring to the data in Figure 4(a), let us assume that a subject is sitting motionless on a rigid support, which induces gluteal muscle tissue deformations of 72 percent. Theoretically, this level of muscle deformation will allow that subject to sit 75 minutes continuously without risking a DTI (Figure 5(a)). If however, cushion $\mathrm{D}$ is used, muscle tissue deformations reduce to 64 percent (Figure 4(a)), and at this deformation level, a subject can, theoretically, sit continuously for 115 minutes without risking a DTI (Figure 5(b)). Hence, though reducing muscle tissue deformations by only 8 percent with respect to the rigid support, cushion D may provide a considerable additional time-40 minutes (53\% more)—of safe sitting. This effect occurs because of the nature of the tolerance curve of muscle cells to deformation [22]. This curve decreases steeply for deformations around 60 to 70 percent (Figure 5) so that even mild reduction in muscle tissue deformation, in the order of 10 percent, can be meaningful in tissue protection time, which can increase substantially as in this example (Figure 5). This example suggests that wheelchair cushions are useful for protecting deep soft tissues subjected to weight-bearing; however, further human studies are needed, particularly in patient populations at increased risk for DTI, before implications to the clinical situation can be made.

Interestingly, foam cushion D, which was the stiffest of all, was found to be the most effective in reducing internal soft-tissue deformations: muscle, fat, and both together (effective soft-tissue) (Figure 4). Also interesting in this regard, a study aimed at characterizing the perception of comfort from wheelchair users' point of view reported that firmer cushions are perceived to be more comfortable [24]. From a biomechanical point of view, a complex interplay is likely between tissue stiffness, cushion stiffness, and the body weight (or trunk weight) [20]. If a cushion is too soft, e.g., cushions A and B in this study, the body sinks into it, and the cushion is so deformed that it creates very little (or a too thin) effective interface between the body and the more rigid underlying foundation. Indeed, we noted that cushions A and B 
induced $\% M, \% F$, and $\% S$ values that were close to those obtained for sitting on the rigid support (Figure 4).

This study is the first to report internal tissue deformations quantitatively in the human buttocks during sitting on wheelchair cushions. In these nondisabled volunteers, we found that deformations under the IT are maximal in muscle tissue, where the mean is around 70 percent, twice more the amount than in superficial fat tissue $(\sim 30 \%)$, consistent with our previous studies of deep soft-tissue strains in the buttocks of nondisabled volunteers as well as wheelchair users with paraplegia [14-15]. Although injury tolerances of muscle versus fat are not yet well characterized, the present tissue deformation data support the hypothesis that DTI originates in skeletal muscle under weight-bearing bony prominences [15-17].
In this study, we used weight-bearing MRI to evaluate wheelchair cushions. Such a method, to our knowledge, has not yet been used. In the past, cushions were evaluated with the use of two major approaches. The first approach was based on clinical outcome of prevention, minimization of onset, or follow-up on healing of pressure ulcers. In these previous studies, patients were assigned into groups, each prescribed with one cushion type, and clinical outcomes between the groups were compared in RCTs or other clinical study design techniques [9-11,25]. Very few RCTs have focused specifically on wheelchair cushions, and even those were inconclusive for an ultimately superior cushion type [3,9,11]. A second approach is biomechanical studies of contact pressures using different cushions [10-12,24]. In light of recent literature

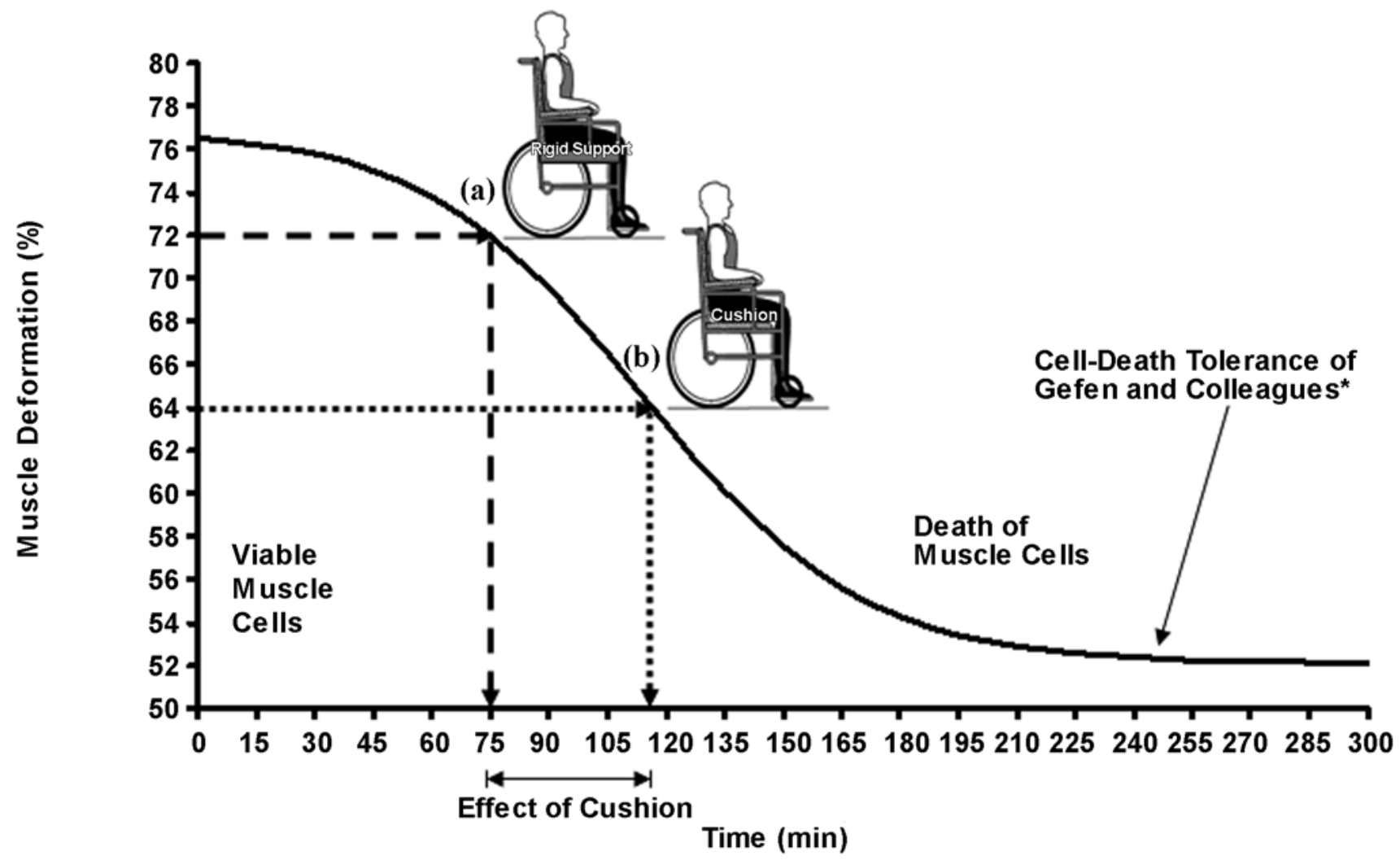

Figure 5.

Theoretical example of how present findings may show difference in muscle cell viability during prolonged sitting with or without cushion. For this purpose, cell-death tolerance of Gefen and colleagues is employed. *Source: Gefen A, Van Nierop B, Bader DL, Oomens CW. Strain-time cell-death threshold for skeletal muscle in a tissue-engineered model system for deep tissue injury. J Biomech. 2008;41(9):2003-12. [PMID: 18501912] DOI:10.1016/j.jbiomech.2008.03.039 (a) Referring to data in Figure 4(a), assume that subject is sitting motionless on rigid support, which induces gluteal muscle tissue deformations of $72 \%$. In theory, this will allow that subject to sit 75 min continuously without risking deep tissue injury (DTI). (b) If, however, cushion D is used, muscle tissue deformations reduce to 64\% (Figure 4(a)), and at this deformation level, subject can sit continuously for 115 min without risking DTI. Hence, though reducing muscle tissue deformations by only $8 \%$ with respect to rigid support, cushion D can add considerable time (40 min [53\% more]) of safe sitting. 
pointing out that contact pressures cannot predict internal mechanical conditions in deep tissues $[4,13,26]$, studies based solely on contact pressure measurements should be cautiously considered. We believe that the present weight-bearing MRI method may better isolate the specific effects of a cushion in DTI risk assessments of individuals; however, at this stage of the research, obviously, this is a hypothesis only, which should be scientifically proven in future clinical studies.

In the present study, we compared the effects of different cushions on internal soft-tissue deformations in the same subjects. The advantage of the MRI was that it clearly demonstrated the anatomy of the internal soft-tissue deformations in each individual during weight-bearing. This feature is particularly important because, in animal studies, internal tissue deformations were shown to be associated directly with DTI [16]. Unlike RCT, MRI can measure quantitatively the fitting of a cushion to the individual. Although the present study was conducted with nondisabled participating subjects, the $\% M, \% F$, and $\% S$ outcome measures can, in the future, directly reflect individual pathoanatomical changes, e.g., those related to disuse muscle atrophy and obesity as seen in patients with spinal cord injury [15,27].

The method used in this study has several potential limitations, which are mostly MRI-related: weight-bearing MR systems are not currently popular; thus their availability is low. Also, MRI may be expensive for use in clinical practice of fitting a cushion to the individual, although if one is considering long-term outcomes, MRI may be cost-effective. In addition, some patients have contraindications for MRI. However, the MRI approach can be extremely useful for the industry in the design phase of cushions, or to some extent in clinical trials, to supplement contact pressure measurements that are currently the gold standard in industry. In the purely clinical context, ultrasound-based systems that are able to demonstrate the anatomy of soft tissues as well as bones can be used for evaluating the same outcome measures obtained presently by the MRI. One recent pilot study already established that using ultrasound to demonstrate soft-tissue thicknesses under the IT in a weight-bearing posture is possible [21], although it might not work with echo-poor cushion materials (e.g., air-filled cushions).

The present study has several additional limitations that are specific to the design. The chair that was used for the MR studies is not identical to a wheelchair. Although the chair was designed and built to simulate overall wheelchair sitting (e.g., in dimensions, as well as in providing armrests and footrests), some effects, like the hammock effect of the wheelchair support [28], were not reproduced in the study design. Also, the chair used in our study is built from plastic, unlike the leather wheelchair seat. These two seats have different properties that may alter the results. Therefore, our data for a "rigid support" (Figure 4) should not be interpreted as "wheelchair without cushion," because a wheelchair seat, even without a cushion, is not completely stiff.

\section{CONCLUSIONS}

This study established a new MRI-based method for measuring the effects of cushions on internal tissue deformations during weight-bearing. We showed that the method is applicable, but it should now be extended to larger groups, including patient groups susceptible to DTI and should also be correlated with clinical outcomes of DTI prevention and healing. Pending these future studies, weight-bearing MRI could systematically support wheelchair cushion design and selection.

\section{ACKNOWLEDGMENTS}

Author Contributions: The first two authors contributed equally to this study.

Study concept and design: N. Shabshin, A. Gefen.

Acquisition of data: G. Zoizner, V. Ougortsin.

Analysis and interpretation of data: N. Shabshin, G. Zoizner, A. Herman, V. Ougortsin, A. Gefen.

Drafting of manuscript: G. Zoizner, N. Shabshin, A. Gefen. Critical revision of manuscript for important intellectual content: N. Shabshin, A. Gefen.

Statistical analysis: A. Herman, G. Zoizner.

Study supervision: N. Shabshin, A. Gefen.

Financial Disclosures: The authors have declared that no competing interests exist.

Funding/Support: This material was unfunded at the time of manuscript preparation.

Additional Contributions: Gil Zoizner performed this study in partial fulfillment of the Medical Doctor thesis requirements of the Sackler Faculty of Medicine, Tel Aviv University, Tel Aviv, Israel.

Additional Information: The Department of Diagnostic Imaging, Sheba Medical Center, Tel Hashomer, Israel, is affiliated with the Sackler Faculty of Medicine, Tel Aviv University, Ramat Aviv, Tel Aviv, Israel.

Institutional Review: The Helsinki committee of Sheba Medical Center, Ramat-Gan, Israel, approved the study (approval 4045/2006), 
and we conducted the study in 2009. Ten nondisabled volunteers were recruited and provided informed consent.

Participant Follow-Up: The authors do not plan to inform participants of the publication of this study.

\section{REFERENCES}

1. Klitzman B, Kalinowski C, Glasofer SL, Rugani L. Pressure ulcers and pressure relief surfaces. Clin Plast Surg. 1998;25(3):443-50. [PMID: 9696904]

2. National Center for Injury Prevention and Control. Spinal cord injury (SCI): Fact sheet [Internet]. Atlanta (GA): Centers for Disease Control and Prevention. [updated 2006 Sep 7; cited 2010 Jan 13]. Available from: http://www.cdc.gov/ Ncipc/factsheets/scifacts.htm/.

3. Black J, Baharestani MM, Cuddigan J, Dorner B, Edsberg L, Langemo D, Posthauer ME, Ratliff C, Taler G; National Pressure Ulcer Advisory Panel. National Pressure Ulcer Advisory Panel's updated pressure ulcer staging system. Adv Skin Wound Care. 2007;20(5):269-74. [PMID: 17473563] DOI:10.1097/01.ASW.0000269314.23015.e9

4. Berlowitz DR, Brienza DM. Are all pressure ulcers the result of deep tissue injury? A review of the literature. Ostomy Wound Manage. 2007;53(10):34-38. [PMID: 17978413]

5. Gefen A. The biomechanics of sitting-acquired pressure ulcers in patients with spinal cord injury or lesions. Int Wound J. 2007;4(3):222-31. [PMID: 17924879] DOI:10.1111/j.1742-481X.2007.00330.x

6. Stekelenburg A, Gawlitta D, Bader DL, Oomens CW. Deep tissue injury: How deep is our understanding? Arch Phys Med Rehabil. 2008;89(7):1410-13. [PMID: 18586145] DOI:10.1016/j.apmr.2008.01.012

7. Black J. Deep tissue injury: An evolving science. Ostomy Wound Manage. 2009;55(2):4. [PMID: 19306535]

8. Diesing P, Hochmann D, Boenick U, Kraft M. [A novel method for patient-oriented assignment of wheelchair cushions based on standardized laboratory testing procedures]. Biomed Tech (Berl). 2005;50(6):188-94. German.

[PMID: 16003920]

DOI:10.1515/BMT.2005.026

9. McInnes E, Bell-Syer SE, Dumville JC, Legood R, Cullum NA. Support surfaces for pressure ulcer prevention. Cochrane Database Syst Rev. 2008;4:CD001735.

[PMID: 18843621]

10. Defloor T, Grypdonck MH. Do pressure relief cushions really relieve pressure? West J Nurs Res. 2000;22(3):335-50. [PMID: 10804896] DOI:10.1177/01939450022044458

11. Reddy M, Gill SS, Rochon RA. Preventing pressure ulcers: A systematic review. JAMA. 2006;296(8):974-98.
[PMID: 16926357]

DOI:10.1001/jama.296.8.974

12. Rithalia S. Assessment of patient support surfaces: Principle, practice and limitations. J Med Eng Technol. 2005;29(4): 163-69. [PMID: 16012067] DOI:10.1080/03091900410001731191

13. Gefen A, Levine J. The false premise in measuring bodysupport interface pressures for preventing serious pressure ulcers. J Med Eng Technol. 2007;31(5):375-80.

[PMID: 17701783] DOI:10.1080/03091900601165256

14. Linder-Ganz E, Shabshin N, Itzchak Y, Gefen A. Assessment of mechanical conditions in sub-dermal tissues during sitting: A combined experimental-MRI and finite element approach. J Biomech. 2007;40(7):1443-54.

[PMID: 16920122]

DOI:10.1016/j.jbiomech.2006.06.020

15. Linder-Ganz E, Shabshin N, Itzchak Y, Yizhar Z, Siev-Ner I, Gefen A. Strains and stresses in sub-dermal tissues of the buttocks are greater in paraplegics than in healthy during sitting. J Biomech. 2008;41(3):567-80. [PMID: 18054024] DOI:10.1016/j.jbiomech.2007.10.011

16. Ceelen KK, Stekelenburg A, Loerakker S, Strijkers GJ, Bader DL, Nicolay K, Baaijens FP, Oomens CW. Compression-induced damage and internal tissue strains are related. J Biomech. 2008;41(16):3399-3404. [PMID: 19010470] DOI:10.1016/j.jbiomech.2008.09.016

17. Ceelen KK, Stekelenburg A, Mulders JL, Strijkers GJ, Baaijens FP, Nicolay K, Oomens CW. Validation of a numerical model of skeletal muscle compression with MR tagging: A contribution to pressure ulcer research. J Biomech Eng. 2008;130(6):061015. [PMID: 19045544$]$ DOI:10.1115/1.2987877

18. Linder-Ganz E, Gefen A. The effects of pressure and shear on capillary closure in the microstructure of skeletal muscles. Ann Biomed Eng. 2007;35(12):2095-2107.

[PMID: 17899378]

DOI:10.1007/s10439-007-9384-9

19. Agam, L, Gefen A. Toward real-time detection of deep tissue injury risk in wheelchair users using Hertz contact theory. J Rehabil Res Dev. 2008;45(4):537-50.

[PMID: 18712639]

DOI:10.1682/JRRD.2007.07.0114

20. Linder-Ganz E, Gefen A. Stress analyses coupled with damage laws to determine biomechanical risk factors for deep tissue injury during sitting. J Biomech Eng. 2009; 131(1):011003. [PMID: 19045919]

DOI:10.1115/1.3005195

21. Lin F, Moran B, Bankard J, Hendrix R, Makhsous M. FEM model for evaluating buttock tissue response under sitting load. Conf Proc IEEE Eng Med Biol Soc. 2004;7:5088-91. [PMID: 17271462] 
22. Gefen A, Van Nierop B, Bader DL, Oomens CW. Straintime cell-death threshold for skeletal muscle in a tissueengineered model system for deep tissue injury. J Biomech. 2008;41(9):2003-12. [PMID: 18501912]

DOI:10.1016/j.jbiomech.2008.03.039

23. Slomka N, Or-Tzadikario S, Sassun D, Gefen A. Membrane-stretch-induced cell death in deep tissue injury: Computer model studies. Cell Mol Bioeng. 2009;2(1):118-32. DOI:10.1007/s12195-009-0046-X

24. Stockton L, Rithalia S. Pressure-reducing cushions: Perceptions of comfort from the wheelchair users' perspective using interface pressure, temperature and humidity measurements. J Tissue Viability. 2008;18(2):28-35.

[PMID: 19329031]

DOI:10.1016/j.jtv.2007.09.006

25. Burns SP, Betz KL. Seating pressures with conventional and dynamic wheelchair cushions in tetraplegia. Arch Phys Med Rehabil. 1999;80(5):566-71. [PMID: 10326923]

DOI:10.1016/S0003-9993(99)90201-0
26. Oomens CW, Stekelenburg A, Ceelen K, Bader DL. A damage threshold for skeletal muscle under sustained mechanical loading. In: Gefen A, editor. The pathomechanics of tissue injury and disease, and the mechanophysiology of healing. Kerala (India): Research Signpost; 2009. p. 313-26.

27. Gefen A. The Compression Intensity Index: A practical anatomical estimate of the biomechanical risk for a deep tissue injury. Technol Health Care. 2008;16(2):141-49. [PMID: 18487860]

28. Iizaka S, Nakagami G, Urasaki M, Sanada H. Influence of the "hammock effect" in wheelchair cushion cover on mechanical loading over the ischial tuberosity in an artificial buttocks model. J Tissue Viability. 2009;18(2):47-54. [PMID: 18926705]

DOI:10.1016/j.jtv.2008.08.001

Submitted for publication August 5, 2009. Accepted in revised form November 10, 2009. 